Basic nutritional investigation

\title{
Prolonged maternal separation induces undernutrition and systemic inflammation with disrupted hippocampal development in mice
}

\author{
Ítalo Leite Figueiredo D.V.M., Ph.D. ${ }^{a}$, Priscila B. Frota M.D. ${ }^{a}$, \\ Davi G. da Cunha M.Sc. ${ }^{\text {, }}$ Ramon da Silva Raposo D.V.M., Ph.D. ${ }^{\text {h }}$, \\ Kildere M. Canuto M.Sc. a , Geanne M. de Andrade Ph.D. ${ }^{b}$, Nuno Sousa M.D., Ph.D. ${ }^{\text {c,d }}$, \\ Sean R. Moore M.D., Ph.D. ${ }^{\text {i }}$, Gregory M. Anstead M.D. ${ }^{\text {, }}$, \\ Jacqueline I. Alvarez-Leite M.D., Ph.D. ' , Richard L. Guerrant M.D. ${ }^{\mathrm{g}}$, \\ Reinaldo B. Oriá D.V.M., Ph.D. ${ }^{\text {a,* }}$
}

\footnotetext{
${ }^{a}$ Laboratory of the Biology of Tissue Healing, Ontogeny and Nutrition, Department of Morphology and Institute of Biomedicine, School of Medicine, Federal University of Ceara, Ceara, Brazil

${ }^{\mathrm{b}}$ Department of Physiology and Pharmacology and Institute of Biomedicine, School of Medicine, Federal University of Ceara, Ceara, Brazil

${ }^{\mathrm{c}}$ Life and Health Sciences Research Institute (ICVS), School of Health Sciences, University of Minho, Campus Gualtar, Braga, Portugal

d ICVS/3B's - PT Government Associate Laboratory, Braga/Guimarães, Portugal

${ }^{\mathrm{e}}$ Department of Biochemistry and Immunology, Institute of Biological Sciences, Federal University of Minas Gerais, Minas Gerais, Brazil

${ }^{\mathrm{f}}$ South Texas Veterans Hospital, San Antonio, TX, USA

${ }^{\mathrm{g}}$ Center for Global Health, Division of Infectious Diseases and International Health, University of Virginia, Charlottesville, VA, USA

${ }^{\mathrm{h}}$ Experimental Biology Core, Health Center, University of Fortaleza, Ceara, Brazil

${ }^{\mathrm{i}}$ Division of Gastroenterology, Hepatology and Nutrition, Department of Pediatrics, Cincinnati Children's Hospital Medical Center, Cincinnati, OH,
} USA

\section{A R T I C L E I N F O}

\section{Article history:}

Received 14 September 2015

Accepted 21 February 2016

\section{Keywords:}

Maternal separation

Malnutrition

Hippocampus

Stereology

Leptin

IGF-1

Inflammation

\begin{abstract}
A B S T R A C T
Objective: Prolonged maternal separation (PMS) in the first 2 wk of life has been associated with poor growth with lasting effects in brain structure and function. This study aimed to investigate whether PMS-induced undernutrition could cause systemic inflammation and changes in nutrition-related hormonal levels, affecting hippocampal structure and neurotransmission in C57BL/6J suckling mice.

Methods: This study assessed mouse growth parameters coupled with insulin-like growth factor-1 (IGF-1) serum levels. In addition, leptin, adiponectin, and corticosterone serum levels were measured following PMS. Hippocampal stereology and the amino acid levels were also assessed. Furthermore, we measured myelin basic protein and synapthophysin (SYN) expression in the overall brain tissue and hippocampal SYN immunolabeling. For behavioral tests, we analyzed the ontogeny of selected neonatal reflexes. PMS was induced by separating half the pups in each litter from their lactating dams for defined periods each day $4 \mathrm{~h}$ on day $1,8 \mathrm{~h}$ on day 2 , and $12 \mathrm{~h}$ thereafter). A total of 67 suckling pups were used in this study.

Results: PMS induced significant slowdown in weight gain and growth impairment. Significant reductions in serum leptin and IGF-1 levels were found following PMS. Total CA3 area and volume were reduced, specifically affecting the pyramidal layer in PMS mice. CA1 pyramidal layer area was also reduced. Overall hippocampal SYN immunolabeling was lower, especially in CA3 field and
\end{abstract}

\begin{abstract}
This work was supported in part by National Institutes of Health (NIH) research grant 5RO1HD053131, funded by the Eunice Kennedy Shriver National Institute of Child Health and Human Development and the NIH Office of Dietary Supplements, and Brazilian grants from CNPq and CAPES (Grant \# RO1 HD053131). The authors would like to thank Dr. Patricia Foley for veterinarian technical support and Dr. José Paulo Andrade for the excellent comments and suggestions to improve this manuscript. N.S. contributed with the stereological studies. I.L.F.
\end{abstract}

and R.B.O. contributed with the behavioral studies. I.L.F., R.B.O., and R.L.G. contributed with the study design, study analysis, and manuscript preparation. G.A.M. and P.B.F. contributed with neurochemical brain analyses. J.I.A.L. and G.M.A. contributed with hormonal and CRP serum analyses. D.G.C., K.M.C., and R.S.R. contributed with animal experimentation and data collection.

* Corresponding author. Tel.: 55085336 68239; fax: +55 8533668445.

E-mail address: rbo5u@virginia.edu (R. B. Oriá). 
dentate gyrus. Furthermore, PMS reduced hippocampal aspartate, glutamate, and gammaaminobutyric acid levels, as compared with unseparated controls.

Conclusion: These findings suggest that PMS causes significant growth deficits and alterations in hippocampal morphology and neurotransmission.

(c) 2016 Elsevier Inc. All rights reserved.

\section{Introduction}

Undernutrition during early postnatal life in children may be associated with a significant slowdown in the rate of central nervous system growth, with reduced brain weight, thinner cerebral cortex, diminished numbers of neurons, deficient myelination, poor neuritic arborization, and several changes in the microscopic features of dendritic spines such as reduction in their width and number, and also cognition impairment [1-4].

In rodents, undernutrition during early life may result in similar reduced brain weight, reduced total cell number, reduced and delayed myelination, loss of axon terminals in the cerebral cortical neurons, and substantial deficits in the synapse-toneuron ratio in some brain regions, indicating a reduction in the total synapse number [5]. Furthermore, recent evidence indicates that long-lasting decrements in hippocampal plasticity occur in mice subjected to early environmental stress, such as maternal separation [6,7]. It has also been shown that undernutrition reduces peripheral circulating concentrations of insulin-like growth factor (IGF-1) [8].

Recently, a negative correlation has been found between IGF1 serum levels and chronic inflammation markers in stunted Zimbabwean infants [9]. However, it remains elusive whether systemic inflammation coupled with low IGF-1 levels, induced by chronic undernutrition, could affect early hippocampal development.

We investigated whether prolonged maternal-offspring separation would cause systemic inflammation and poor growth and assessed its effects on the hippocampus structure and amino acid neurotransmitter levels in 2-wk-old mice, a time in which the hippocampus relies on a strong postnatal plasticity [10]. To relate systemic inflammation and nutritional status, we assessed circulating levels of C-reactive protein and nutrition-related hormones in the blood sera following undernutrition.

\section{Materials and methods}

Prolonged maternal separation model

C57BL/6J wild-type mice were purchased from Charles River laboratories. Either purchased pregnant mice or breeding pairs were used to obtain the study pups. Detectably pregnant mice (at $\sim 12 \mathrm{~d}$ pregnant) were then caged individually, with free access to standard rodent chow and water, and were monitored daily for delivery, termed Day (D) 0 . Newborn litters were adjusted to 6 to 8 pups. Undernutrition was induced by separating half the pups in each litter from their lactating dams for defined periods each day ( $4 \mathrm{~h}$ on D4; $8 \mathrm{~h}$ on D5 and $12 \mathrm{~h}$ thereafter). Pups were separated between 8:00-10:00 am daily: All pups were breastfed and rested in their cages. In rare cases of encountering breastfeeding, pups were left undisturbed until breastfeeding was finalized. Litters with about the same male:female ratio were selected for the study entry. The separation protocol was not conducted in newborn mice $(<4 \mathrm{~d}$ old $)$ to guarantee more colostrum intake and to avoid perinatal mortality. A total of 67 pups were used in this study.

The maternal separation protocol was adapted from Calikoglu et al [8]. This method has the advantage of providing littermate controls and well-nourished pups to compare with undernourished ones. Weight and tail length were recorded daily until the pups were humanely killed immediately before the separation handling. A thermal pad was used to warm the pups during daily measurements $\left(27 \pm 2^{\circ} \mathrm{C}\right)$. Care was taken to assure the same level of handling for all experimental mice. Protocols from this study were previously approved by the
Institutional Animal Care and Use Committee at the University of Virginia and the University of Fortaleza (protocol \#15005). All efforts were made to minimize the number of animals used and their suffering.

\section{Nutritional status}

To assess changes in growth and weight gain, daily tail length and body weight were analyzed, the former as a measure of linear skeletal growth Experimental mice were monitored carefully by daily inspection of weight and tail length during the suckling time on days 4 to 14 . Tail length was recorded by means of gently measuring the tail from the base to the tip, using a digital caliber and a card board (to the nearest $0.1 \mathrm{~mm}$ ). All measurements were conducted before starting the procedures of daily mice separation. Care was taken to keep the same degree of handling during this process for all mice.

\section{Neonatal reflex ontogeny}

We assessed the ontogeny of selected neonatal reflexes along the first $2 \mathrm{wk}$ of life, including cliff avoidance, surface righting, dorsal immobility, and swimming behavior [11,12]. The cliff avoidance reflex test is used to assess the integration of exteroceptive input (vibrissae) and locomotor output, providing information concerning motor skills as well as sensory function and/or processing [13,14]. The offspring is placed on a platform elevated $10 \mathrm{~cm}$ above a table top. The forelimbs and snout of the animals are positioned so that the edge of the platform passes just behind an imaginary line drawn between the eye orbits. Avoidance is scored by reflex latency between being placed on the edge and turning until it is parallel to the edge of the table $(0=$ no response, latency $>60$ s; $1=$ response $<10 \mathrm{~s} ; 2=$ $<5 \mathrm{~s}$ ). The surface righting reflex is a measure of the capacity to return to a prone position. Pups were placed on their backs on a smooth surface, and the time required to right themselves to a position where the four limbs touches the surface was measured. The time is scored as follows: $2=$ righting $\leq 1$ s, $1=$ righting $>1 \mathrm{~s}$ and $\leq 2 \mathrm{~s}, 0=$ righting $>2 \mathrm{~s}$. The swimming behavior test is used to assess navigational and motor development. Pups are placed into a tank with water temperature maintained at $27 \pm 1^{\circ} \mathrm{C}$ and swimming behavior was rated for direction (straight $=3$, circling $=2$, floating $=1$ ) and head angle (ears out of water $=4$, ears half out of water $=3$, nose and top of head out of water $=2$, and unable to hold head up $=1$ ). Dorsal immobility (tonus immobility) was measured by suspending the mice by the back up to approximately $10 \mathrm{~cm}$ above a flat surface. The procedure is performed with the aid of a modified twissor, covered by rubber on its tip to avoid trauma. The dorsal immobility scores the latency time (in s) until the mouse moves to escape the grasping and is related to ventrolateral mesencephalic periaqueductal gray matter activity [15]. $\mathrm{N}=8$ for PMS and $\mathrm{N}=6$ unseparated mice were used for all behavioral tests done.

\section{Systemic inflammation marker}

To find whether prolonged maternal separation could cause systemic inflammation, we measured serum C-reactive protein ( $N=10$ for both PMS and unseparated mice), which is a liver acute phase protein released during unspecific inflammatory responses. High sensitivity $C$ reactive protein was assessed using a commercial kit (Labstest and Bioclin, Belo Horizonte, Brazil).

\section{Nutrition and stress-related hormone serum levels}

To find whether prolonged maternal separation could cause changes in nutrition and stress-related hormones (leptin, adiponectin, and corticosterone), serum levels were assessed. On day 14 , blood was drawn from some mice following decapitation ( $\mathrm{N}=10$ per group). We also assessed IGF-1 serum levels as IGF-1 deficiency has been associated with stunting. These hormones were measured in serum samples using an enzyme-linked immunosorbent assay according to the manufacturer's instructions (R\&D Systems, Minneapolis, MN, USA).

Hippocampal structure and amino acid levels

Hippocampal stereology

A total of 14 male C57BL/6J mice were used in this experiment. Mice were divided into the following two groups: unseparated mice $(n=7)$ and prolonged 
maternal separated mice $(n=7)$. Hippocampal tissue was collected on day 14 (the end point), following a transcardiac perfusion-fixation with Palay solution (containing $1 \%$ formaldehyde and $1 \%$ glutaraldehyde in $0.12 \mathrm{M}$ phosphate buffer at $\mathrm{pH}$ 7.2) [16] and immediately immersed in the same solution for stereological analyses.

After euthanasia the hippocampus was dissected from the brain and halved. Each hemi-hippocampus was systematically, uniformly, and randomly (SUR) selected $[17,18]$ between left and right and weighed. Subsequently, the selected hemi-hippocampus (left or right) was manually straightened along its septotemporal axis to diminish the anatomical organ curvature.

Subsequently, the straightened hippocampus was embedded in a $10 \%$ agar solution and exhaustively cut into a thin section ( $100 \mu \mathrm{m}$-thick) followed by a thick section ( $1 \mathrm{~mm}$-thick), alternately and using a vibratome (VT $1000 \mathrm{~S}$, Leica Camera AG, Wetzlar, Germany) [19]. Sections were orthogonal to hippocampus' long axis and a fraction $\left(10^{-1}\right)$ of those paired sections (thin and thick sections) was SUR selected. The average interval $(K)$ between the section pairs was $400 \mu \mathrm{m}$. Thin sections were collected onto glass slides, stained with $1 \%$ alcoholic toluidine blue solution, dehydrated in progressive ethanol concentrations, mounted under a cover slip with DPX (Fluka, Sverige, Sweden) and used not only to record the exact position of the studied layer in the hippocampus (i.e. mapping sections [19]) but also for the estimation of postembedding hippocampus and hippocampal layer volumes using Cavalieri's principle.

Thick sections were used to produce vertical, uniform, and random sections [20]. The first of the thick sections were positioned onto a transparent plate of Silgard in the center of a circle with $36\left(360^{\circ}\right)$ equidistant divisions along the perimeter. Next step, a random number between 0 and 36 was generated using a random number table (SUR selected) [19].

Subsequently, a transparent cutting guide containing lines was placed onto the thick section at the same selected angle. Finally, a razor blade was used to produce bars from the sections guided by the lines in the cutting guide.

Each bar containing hippocampus was rotated by $90^{\circ}$ around the vertical axis to the sections and allowed for vertical, uniform, and random sections parallel to the vertical axis. The bars from each section were then re-embedded in a $10 \%$ agar solution and exhaustively sectioned at $50 \mu \mathrm{m}$-thick using a vibratome.

Thick sections (from bars) were collected onto glass slides, stained with an $1 \%$ alcoholic toluidine blue solution, dehydrated in progressive ethanol concentrations, mounted under a cover slip with DPX (Fluka), and were used to simultaneously estimate the number of hippocampal neurons.

Section images were acquired using a Leica DMR Microscope coupled with a Digital Camera PLA622 (Pixellink) and stereological software New Cast Visiopharm (version 2.16.1.0, Horsholm, Denmark). The area of the unbiased counting frame used was $5,000 \mu \mathrm{m}^{2}$ [21]. Before starting the counting procedure, a z-axis distribution (calibration) was performed to know the neuron distribution throughout section thickness and establish the dissector height, which was $20 \mu \mathrm{m}$. Section thickness was measured in every second field of view using the central point on the unbiased counting frame. The neuron nucleus was defined as the counting unit.

In this study the whole hippocampal structure, including the granular cell layer of dentate gyrus (DG) and the CA1 and CA3 pyramidal cell layers, was defined at all levels of sectioning according to the stereotaxic coordinates published elsewhere [22].

\section{Hippocampus volume: $V(H I P)$}

Hemi-hippocampus fresh weight was converted into volume to estimate tissue shrinkage. The formula used was $\mathrm{V}=\mathrm{m} / \mathrm{d}$, where $\mathrm{V}$ stands for volume, $\mathrm{m}$ for mass, and d for density. The specific density was $1.04 \mathrm{~g} / \mathrm{cm}^{3}$ [19]. We report in the Results the bilateral volume, which was elicited by multiplying V (HIP) by 2 since the left or right hemi-hippocampus was SUR sampled [18].

Volume of CA1, CA3, and dentate gyrus layers: $V$ and $V\left(H I P_{\text {post-emb }}\right)$

The volume of the examined CA layer and the postembedding volume of the selected hemi-hippocampus were estimated using Cavalieri's principle on the thin sections $(100 \mu$ m-thick $)$. Then, $\mathrm{V}$ or $\mathrm{V}\left(\mathrm{HIP}_{\text {post-emb }}\right)=\Sigma \mathrm{P} \cdot \mathrm{ap} \cdot \mathrm{BA} \cdot \mathrm{K}$, where $\mathrm{P}$ is the number of test points hitting the tissue (region or the whole hippocampus; we have used on average 100 [hippocampal region] and 200 [HIP] points per animal), ap is the area associated with each test point, BA is the mean block advance (or mean section thickness $=100 \mu \mathrm{m}$ ), and $\mathrm{K}$ is the distance between the sections sampled.

The error variance of Cavalieri's estimator was estimated according to Nyengaard [23]. Therefore, the error variance of Cavalieri's estimate was 0.04 for group 1, 0.04 for group 2, 0.03 for group 3, 0.03 for group 4, and 0.04 for group 5 .

The volume shrinkage was then calculated as:

Volume shrinkage $=1$ - volume after: volume before, according to HosseiniSharifabad M, Nyengaard [19].
Numerical density CA1 and CA3 pyramidal cells and DG granule cells: $N_{V}$

The optical dissector was used to estimate the numerical density of CA1 neurons in a given hemi-hippocampus. The formula for $\mathrm{N}_{\mathrm{V}}$ estimation is: $\mathrm{N}_{\mathrm{V}}:=$ $\overline{t q^{-}} / B A \cdot \sum Q^{-} / h \cdot a(p) \cdot \sum P$ where $\Sigma Q^{-}$is the total number of particles counted by dissectors, $\mathrm{a}$ is the counting frame area, $\mathrm{p}$ is the number of reference points per counting frame, and $\sum P$ is the total number of reference points in each counting frame, which hit the reference volume, the studied hippocampal layer, $\bar{t} q^{-}$is the $Q^{-}$-weighted mean section thickness measured, and BA is the mean block advance in the vibratome.

Total number of CA1, CA3 pyramidal cells, and DG granule cells: $N$

The total number of neurons was estimated by multiplying the numerical density of the studied hippocampal layer neurons by the volume of the respective layer. Therefore:

\section{$N:=N v \cdot V$}

The bilateral number was obtained by simply multiplying $\mathrm{N}$ (neuron estimate.2) since the left or right hemi-hippocampus was SUR sampled [18].

The error variance of total neuron number (Cavalieri's estimator $[\mathrm{N}]$ ) was estimated as shown in Gundersen et al. [17] and Nyengaard [23].

\section{Hippocampal amino acids levels}

Since the hippocampal neurotransmission activity has been found to be disturbed by early maternal separation challenge [24], we assessed hippocampal amino acid levels following PMS. To avoid neurochemical changes due to anesthesia, a subset of 19 mice ( $\mathrm{N}=10$ for PMS and $\mathrm{N}=9$ for unseparated mice) were euthanized by decapitation to assess hippocampal amino acid levels. Dissected hippocampi were obtained from 14-d-old experimental pups and stored at $-80^{\circ} \mathrm{C}$ until analyzed. Analyses of amino acids (aspartate, glutamate, taurine, and gamma-aminobutyric acid [GABA]) were carried out from dissected hippocampus using a high-performance liquid chromatography apparatus (Shimadzu, Kyoto, Japan), and a fluorimetric detection method. Briefly, frozen tissue specimens were homogenized in $0.1 \mathrm{M}$ perchloric acid and sonicated for $30 \mathrm{~s}$ at $25^{\circ} \mathrm{C}$. After sonication, samples were centrifuged at $15000 \mathrm{rpm}$ for $15 \mathrm{~min}$ at $4^{\circ} \mathrm{C}$. Supernatants were removed and filtered through a membrane $(0.22 \mu \mathrm{m}$, Merck Millipore, Billerica, MA, USA), and the amino acids were derivatized with mercaptoethanol and O-phthaldialdehyde. O-phthaldialdehyde derivatives were then separated on a C18 column $(150 \mathrm{~mm} \times 4.6 \mathrm{~mm}$; Shimadzu) and after derivatization, amino acids were separated, using a mobile phase consisting of sodium phosphate buffer ( $50 \mathrm{mM}, \mathrm{pH} 5.5$ ) and $20 \%$ methanol. The area of each peak was determined using Shimadzu software and compared with the peak area of the corresponding external standard. Amino acid concentrations were expressed as $\mu \mathrm{mol} / \mathrm{g}$ of wet tissue.

\section{Brain plasticity markers}

To evaluate brain plasticity following PMS, we assessed the protein expression of synaptophysyn (SYN), a synaptic vesicle protein and therefore a marker of synaptic activity and myelin basic protein (MBP), a constitutive protein associated with the myelin sheet, in the overall brain tissue. In a subset of mice the entire brain was carefully dissected and immediately frozen in liquid nitrogen. Thawed specimens were pulverized with an electric homogenizer (ultra-Turrax homogenizer, Sigma-Aldrich, St. Louis, MO, USA) containing lysis buffer and then transferred to test tubes with protease inhibitor cocktail and centrifuged at 14 $000 \mathrm{rpm}$. Supernatants were assayed using the bicinchoninic acid method, with the BCA Protein Assay Kit (Pierce, Rockford, IL, USA) to standardize $50 \mu \mathrm{g}$ of protein product. Samples were loaded into $12.5 \%$ denaturizing polyacryamide mini gels (Bio-Rad, Hercules, CA, USA), and gels were transferred overnight and then blotted onto nitrocellulose membranes. Membranes were incubated with either rabbit SYN or MBP antibodies (at dilution of 1:2000 and 1:500 respectively) for $1 \mathrm{~h}$, rinsed three times in rinsing buffer, and then incubated in a secondary antibody (1:5000) and rinsed as described. Each membrane was washed and exposed to Kodak X-Omat AR film (Kodak, Rochester, NY, USA). Stripped blots were later incubated with GAPDH antibodies as an internal control. In addition, we evaluated SYN immunolabeling in paraffin-embedded hippocampi of the experimental mice, as described elsewhere [25]. At least five hippocampus samples per group were used for both western blot and immunohistochemistry.

\section{Statistical analysis}

Unpaired Student t test was used to assess mean differences between groups; $P<0.05$ was considered statistically significant. Data are represented as mean \pm standard error. Statistical analyses were performed using Graph Pad Prism 6.0 (La Jolla, CA, USA). 


\section{Results}

\section{Nutritional status}

In this model, we have found significant slower linear growth and poor weight gain after prolonged maternal separation during suckling, as measured by daily tail length and weight gain and as compared to nourished, non-separated controls, $(P<0.05)$ (Fig. 1). As expected, linear growth deficits appeared later on PND 11, 1 wk after the onset of the maternal separation protocol, indicating chronic under nutrition. Significant weight faltering was found earlier on PND 6, $2 \mathrm{~d}$ after the onset of the maternal separation protocol. On day 14 , at the end point, nourished mice displayed an average 1.6-fold higher body weight gain versus challenged mice (Fig. 1). In addition, PMS mice were three standard deviations below the mean tail length of the unseparated nourished controls, characterizing a poor linear length growth that is analogous to children stunting.

\section{Neonatal reflex ontogeny}

Prolonged maternal separation induced deficits in surface righting and dorsal immobility reflexes, which were seen in the end of the second week of life (on D 14; $P<0.05$ ) (Fig. 2). No significant differences were found regarding swimming behavior and cliff avoidance over the first $2 \mathrm{wk}$.

\section{CRP serum levels}

Prolonged maternal separation caused significant increase in CRP serum levels $(6.6 \pm 1.8 \mathrm{mg} / \mathrm{L}, \mathrm{n}=10)$ when compared with

\section{Weight and Tail Length}

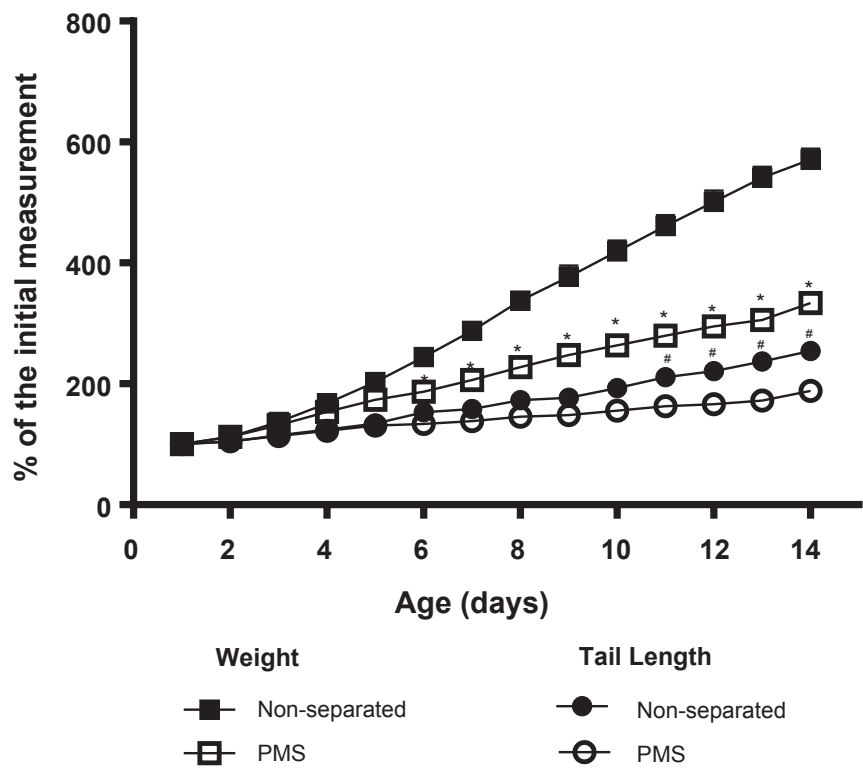

Fig. 1. Relative weight and tail length gain from experimental mice during timedprolonged maternal separation (PMS) $(\mathrm{N}=16)$ and respective non-separated controls $(\mathrm{N}=10)$. Curves are presented as percentage of initial weight at postnatal day 1 . Results are expressed in mean \pm SEM and were analyzed by unpaired Student t test. ${ }^{*} P<0.05$ vs non-separated controls. Results are expressed in mean \pm SEM and were analyzed by unpaired Student $t$ test. ${ }^{\#} P<0.05$ vs separated controls. the well-nourished counterparts $(4.9 \pm 1.0 \mathrm{mg} / \mathrm{L}, \mathrm{n}=10$ $P=0.010$ ) (Fig. 3).

\section{Nutrition and stress related hormones}

We found significant reductions in leptin and IGF-1 serum levels following prolonged maternal separation when compared with the non-separated controls (Fig. 4). No significant differences were found with corticosterone $(79.7 \pm 35.9 \mathrm{ng} / \mathrm{L}, \mathrm{n}=5$ versus $152.3 \pm 85.5, \mathrm{n}=8, P=0.1)$ and adiponectin $(8176.2 \pm 0.7 \mathrm{ng} / \mathrm{L}, \mathrm{n}=5$ versus $8202.7 \pm 1996.8, \mathrm{n}=8, P=0.9)$ for the non-separated and PMS-groups, respectively.

\section{A Surface Righting}

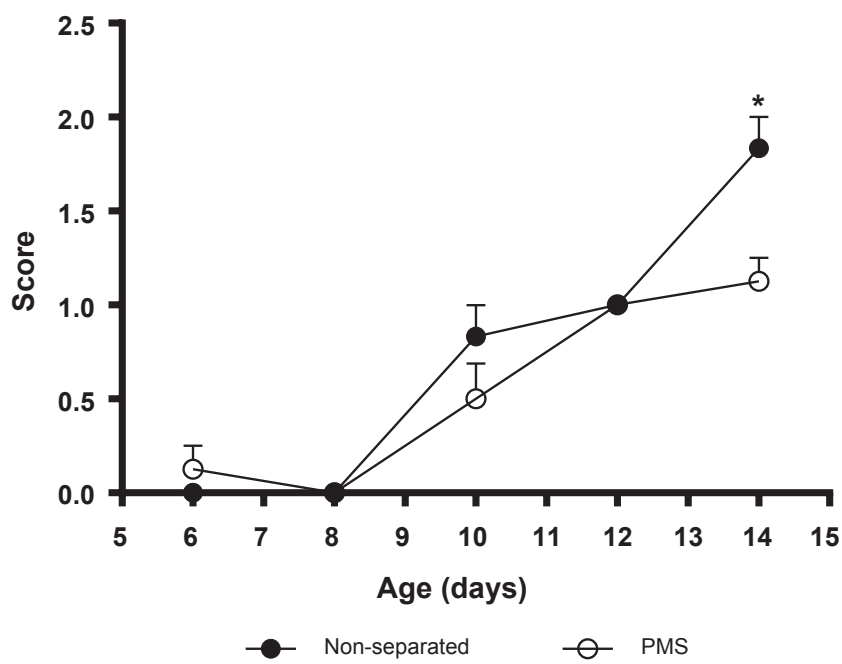

B Dorsal Immobility

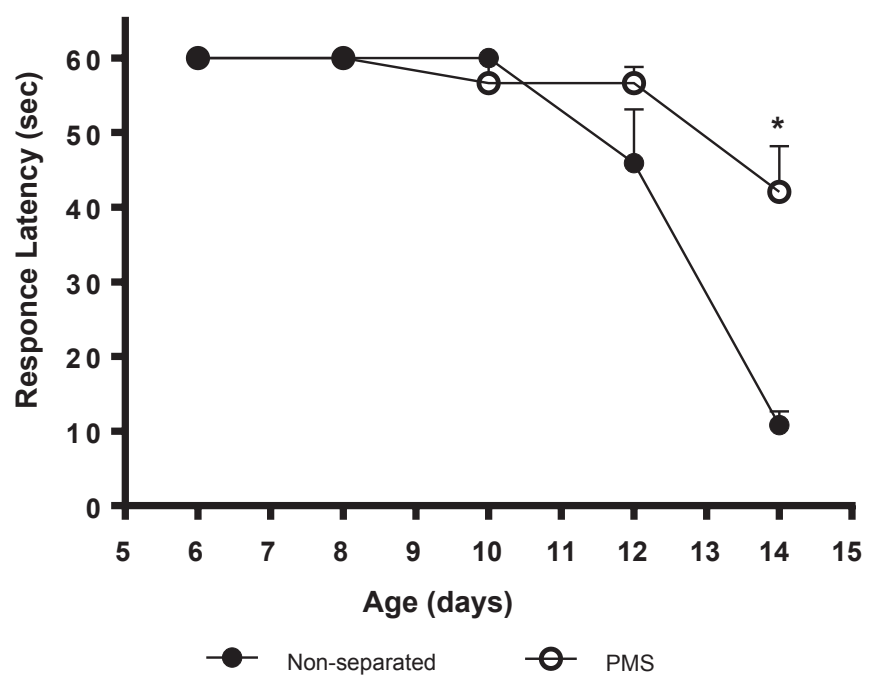

Fig. 2. Behavioral tests (A: surface righting) and (B: dorsal immobility) conducted in the first two weeks of life in the non-separated $(\mathrm{N}=6)$ and prolonged maternal separated (PMS) $(\mathrm{N}=8)$ groups. For the surface righting testing, results are shown in scores. The performed time was scored as follows: 2-righting $\leq 1 \mathrm{sec}$; 1 -righting $>1$, and $\leq 2 \mathrm{sec} ; 0->2 \mathrm{sec}$. For the dorsal immobility test, data are shown as latency mean time in seconds. The results are shown as mean \pm SEM and were analyzed by unpaired Student t test. ${ }^{*} P<0.05$ vs non-separated controls. 


\section{C-reactive protein}

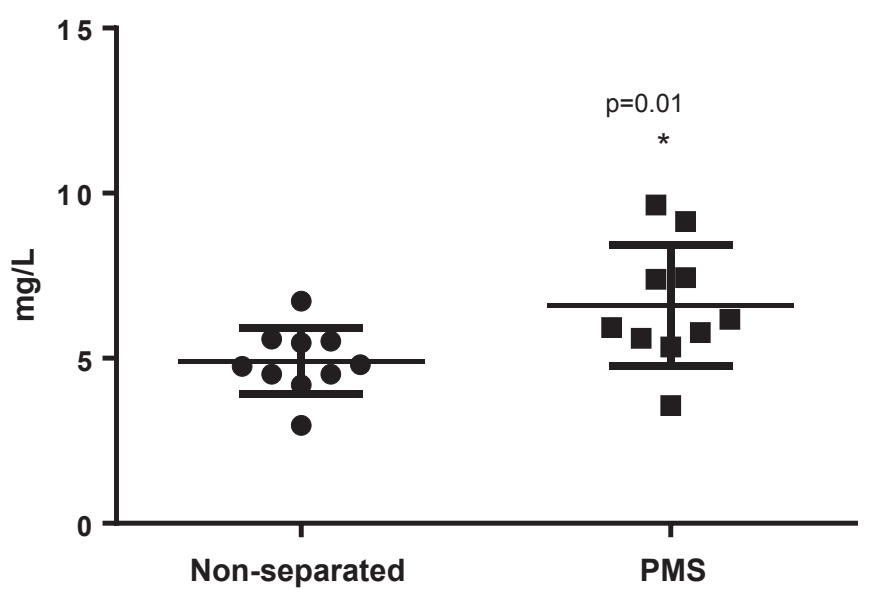

Fig. 3. C-reactive protein serum levels of experimental mice following prolonged maternal separation (PMS) $(\mathrm{N}=10)$ and the respective unseparated-controls $(\mathrm{N}=10)$ (on day 14). Data are expressed in $\mathrm{mg} / \mathrm{L}$. Results are shown as mean \pm SEM and were analyzed by unpaired Student $t$ test. ${ }^{*} P<0.05$ vs nonseparated controls.

\section{Hippocampal stereology}

The hemi-hippocampus shrinkage volume (\%) was estimated to be (mean \pm SD) $4.75 \pm 1.22$ (group 1); $5.56 \pm 1.52$ (group 2); $4.16 \pm 1.21$ (group 3); $5.05 \pm 1.17$ (group 4); and $5.75 \pm 1.12$ (group 5). No correction for global shrinkage was performed since intergroup differences were not statistically significant $(P=0.13)$. The malnutrition challenge reduced the total volume and area of the CA3 hippocampal field and CA3 pyramidal layer volume. In addition, we found reduced CA1 pyramidal layer area.

\section{IGF-1 and Leptin}

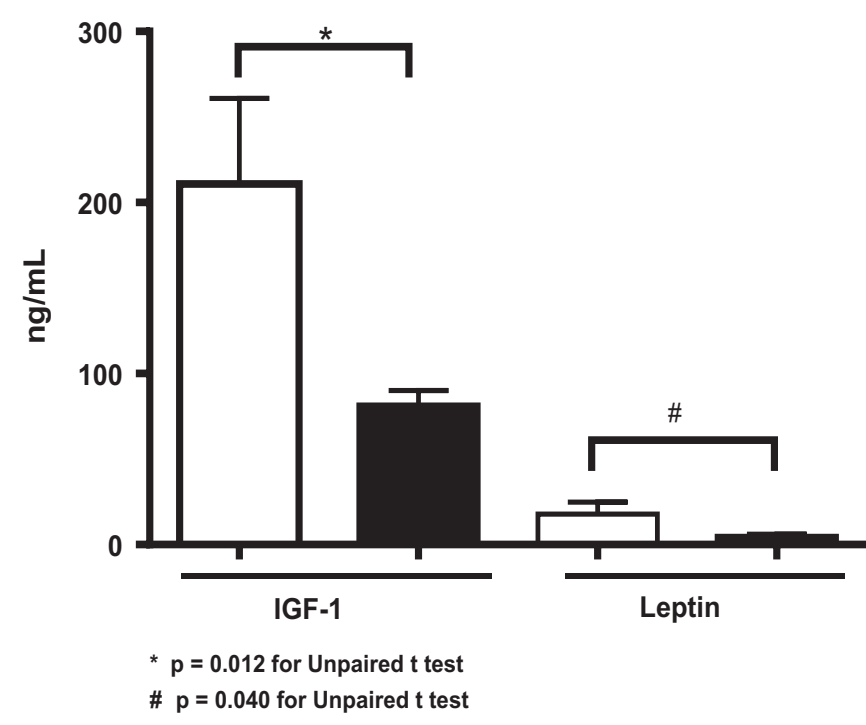

Fig. 4. IGF-1 and leptin serum levels of experimental mice following prolonged maternal separation and the respective unseparated-controls (on day 14). At least five mice were used for these analyses. Data are expressed in $n g / m L$. Results are shown as mean \pm SEM and were analyzed by unpaired Student $t$ test. ${ }^{*}{ }^{*} P<0.05$ vs non-separated controls.
No other significant changes were found regarding the hippocampal CA1 and CA3 fields and DG between experimental groups (Table 1).

\section{Hippocampal amino acid levels}

The amino acid assessment in the hippocampus using the high-performance liquid chromatography method showed that PMS induced significant decreased concentrations ( $\mu \mathrm{mol} / \mathrm{g}$ tissue) of aspartate $(3944.6 \pm 317.1, \mathrm{n}=9$ versus $636.5 \pm 33.3$, $\mathrm{n}=10)$, glutamate $(730.2 \pm 16.6, \mathrm{n}=9$ versus $584.1 \pm 47.1$, $\mathrm{n}=10)$, glycine $(155.5 \pm 3.9, \mathrm{n}=9$ versus $135.9 \pm 4.7, \mathrm{n}=10)$, and GABA (598.9 $\pm 10.9, \mathrm{n}=9$ versus $246.7 \pm 27.9, \mathrm{n}=10)$ $(P<0.05)$, compared to the unseparated control group (Fig. 5).

\section{SYN and MBP}

We could not find significant different expression of either SYN or MBP in the overall brain tissue from experimental mice. Qualitatively there was a more conspicuous and stronger SYN immunolabeling in overall hippocampus from the unseparated compared with the PMS-mice, particularly in the DG and CA3 regions (Fig. 6).

\section{Discussion}

In our study, we have used a PMS model characterized by repetitive and long-term maternal-offspring separation in the first $2 \mathrm{wk}$ of life to induce moderate-to-severe under nutrition. The first 2 wk of life in mice is a key time window for brain development, especially in the cerebellum, cerebral cortex, and the hippocampus [10]. In this model, PMS mice were found to have a poor linear growth (analogous to human stunting) and were profoundly underweight (below two standard deviations of the control mean). Indeed, neonatal PMS induced a chronic malnutrition status.

In addition, surface righting and dorsal immobility were affected by maternal separation only in the end of the experimental protocol (day 14), which may indicate more cumulative adverse effects of maternal separation. Delays in the development of some neonatal reflexes were found by Ladd et al. (2010) in a study of malnutrition using larger litters in the second week of postnatal life [25]. In the same study, the authors also reported a beneficial effect of zinc supplementation $(500 \mathrm{mg} / \mathrm{L}$ in the drinking water for animals) in improving some of the parameters [25].

The surface righting reflex involves the vestibular-cerebellar neural pathways [26], suggesting that the SMP affects negatively the cerebellum development, which has a strong postnatal development component. Interestingly, a transient increase in some markers of cerebellar myelination and neurotrophic factors was found after a 3-h maternal separation compared to unseparated controls, which may indicate a compensatory response to rescue normal cerebellar development [27]. Our current study using a chronic maternal deprivation model has not assessed morphological changes in the cerebellum that may have contributed to delays in the acquisition of neonatal reflexes. In support of our findings, Zhang et al. also found deficits in surface righting in the mouse offspring of food-restricted mothers [28].

The dorsal immobility response (or tonic immobility) involves the periaqueductal gray matter (PGM) of the midbrain. This structure has a role in pain modulation and defensive behavior and the fine motor output for basic survival [28]. The PGM keeps anatomical and functional connections with 
Table 1

Hippocampal stereological estimations

\begin{tabular}{|c|c|c|c|c|c|c|c|c|c|}
\hline \multirow[t]{2}{*}{ Hippocampal fields } & & \multicolumn{4}{|l|}{ Non-separated } & \multicolumn{4}{|l|}{ PMS } \\
\hline & & $\mathrm{N}^{\circ}$ cells $\left(10^{4}\right)$ & Volume $\left(10^{8}\right)$ & Area $\left(10^{5}\right)$ & № cells/Area & $\mathrm{N}^{\circ}$ cells $\left(10^{4}\right)$ & Volume $\left(10^{8}\right)$ & Area $\left(10^{5}\right)$ & No cells/Area \\
\hline \multirow[t]{4}{*}{$\overline{D G}$} & $\mathrm{Gr}$ & $7.7 \pm 1.6$ & $1.3 \pm 0.2$ & $8.0 \pm 1.5$ & $0.1 \pm 0.02$ & $8.0 \pm 1.0$ & $1.2 \pm 0.1$ & $5.7 \pm 0.4$ & $0.1 \pm 0.01$ \\
\hline & Mol & - & $2.1 \pm 0.5$ & $12.7 \pm 3.1$ & - & - & $1.8 \pm 0.1$ & $9.9 \pm 0.9$ & - \\
\hline & Pol & - & $1.3 \pm 0.3$ & $7.2 \pm 1.8$ & - & - & $0.7 \pm 0.1$ & $3.6 \pm 0.7$ & - \\
\hline & Total & - & $4.7 \pm 0.6$ & $27.9 \pm 5.9$ & - & - & $3.7 \pm 0.4$ & $19.2 \pm 2.0$ & - \\
\hline \multirow[t]{4}{*}{ CA1 } & Pyr & $4.4 \pm 0.5$ & $1.0 \pm 0.08$ & $7.3 \pm 0.5$ & $0.06 \pm 0.008$ & $4.5 \pm 0.4$ & $1.1 \pm 0.06$ & $5.7 \pm 0.3^{*}$ & $0.07 \pm 0.009$ \\
\hline & Or & - & $1.9 \pm 0.1$ & $10.2 \pm 0.9$ & - & - & $1.8 \pm 0.1$ & $10.2 \pm 0.8$ & - \\
\hline & Rad & - & $1.8 \pm 0.1$ & $10.1 \pm 1.0$ & - & - & $1.7 \pm 0.1$ & $9.9 \pm 0.7$ & - \\
\hline & Total & - & $4.7 \pm 0.2$ & $27.6 \pm 2.3$ & - & - & $4.6 \pm 0.2$ & $25.8 \pm 1.7$ & - \\
\hline \multirow[t]{4}{*}{ CA3 } & Pyr & $4.4 \pm 0.4$ & $1.6 \pm 0.1$ & $10.4 \pm 1.3$ & $0.04 \pm 0.005$ & $4.6 \pm 0.5$ & $1.2 \pm 0.1^{*}$ & $7.2 \pm 0.7$ & $0.06 \pm 0.007$ \\
\hline & Or & - & $2.3 \pm 0.3$ & $12.6 \pm 1.9$ & - & - & $1.5 \pm 0.1$ & $8.5 \pm 0.7$ & - \\
\hline & Rad & - & $1.5 \pm 0.1$ & $8.8 \pm 1.0$ & - & - & $1.2 \pm 0.1$ & $6.5 \pm 0.8$ & - \\
\hline & Total & - & $5.4 \pm 0.4$ & $31.8 \pm 3.8$ & - & - & $3.9 \pm 0.3^{*}$ & $22.2 \pm 1.9^{*}$ & - \\
\hline
\end{tabular}

CA1, cornus ammonis 1; CA3, cornus ammonis 3; DG, dentate gyrus; Gr, granular cells; Or, oriens layer; PMS, prolonged maternal separated mice; Mol, molecular layer; Pol, polymorphic layer; Pyr, pyramidal cell; Rad, stratum radiatum layer; Total, sum of each of the hyppocampal field layers

$\mathrm{N}=7$ for non-separated and PMS groups.Data are expressed as mean \pm standard error of the mean (SEM)

$* P<0.05$ versus the non-separated group by unpaired Student $t$ test.

structures such as the thalamus, hypothalamus, and amygdala $[29,30]$. However, impairment of PGM with involvement of hippocampus due to chronic malnutrition has not yet been reported.

Barros and colleagues adapted a low protein and high carbohydrate diet to mimic the dietary characteristics of endemic malnutrition regions of Brazil. They found delays in the maturation of most of the locomotion-related neonatal reflexes tested in the first $3 \mathrm{wk}$ of life in offspring breastfed by undernourished dams [31].

Another important finding of this study was a noticeable reduction in hippocampal SYN immunostaining of PMSchallenged mice, especially in the CA3 and DG regions. However, we could not find differences in SYN and MBP in the total brain tissue. These findings suggest that the hippocampus is highly sensitive to the PMS-induced effects. Wistar rats separated from dams for $4 \mathrm{~h}$ daily for $18 \mathrm{~d}$ in the first $2 \mathrm{wk}$ of life did

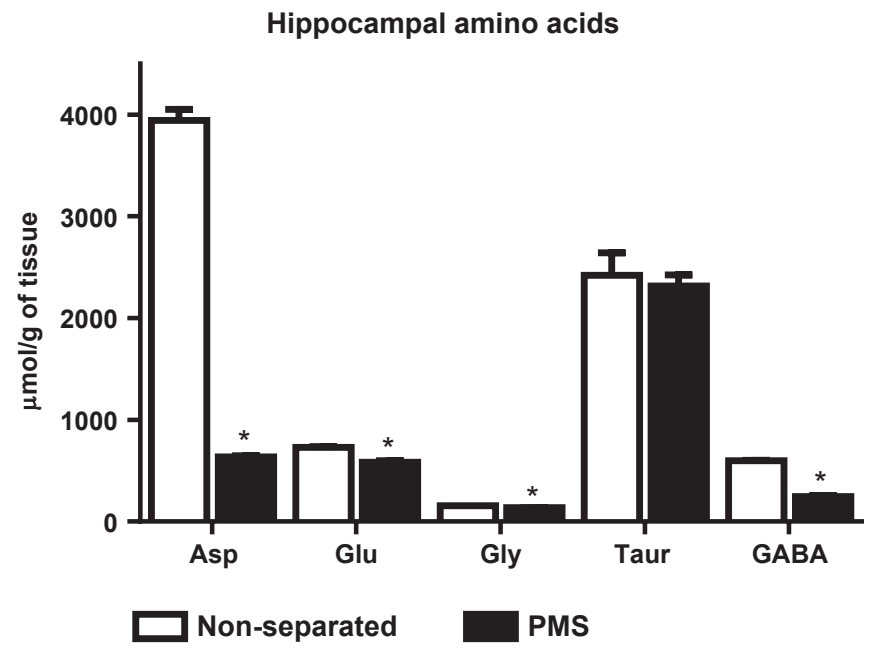

${ }^{*} \mathrm{p}<0.001$ by Student $T$ test

Fig. 5. Hippocampal amino acid levels of experimental mice following prolonged maternal separation (PMS) $(\mathrm{N}=10)$ and the respective unseparated-controls $(\mathrm{N}=9)$, detect by high-performance liquid chromatography on day 14 . Data are expressed in $\mu \mathrm{mol} / \mathrm{g}$ of tissue. Results are shown as mean \pm SEM and were analyzed by unpaired Student t test. ${ }^{*} P<0.05$ vs non-separated controls. not show hippocampal CA1 and CA3 remarkable increase in SYN expression on days 25 to 60 compared to the unseparated controls and did not show the same degree of needed pruning later on postnatal day 100 in the same hippocampal fields [32]. The hippocampal layers are the following: alveus, stratum oriens, stratum pyramidale (with pyramidal cell bodies), stratum radiatum, and stratum lacunosum-moleculare in the hippocampal proper (in the cornus amnonis fields); in the dentate gyrus area: stratum moleculare, stratum granulosum (granular cell bodies), and the hilus of the fascia dentata [33].

The hippocampus is a brain region that seems to be particularly vulnerable to the effects of stress due to a high density of glucocorticoid receptors and susceptibility to epigenetic modulation [34]. Early exposure to stress or corticosteroids can cause hippocampus remodeling (or atrophy) [35], effects which may be associated with a reduction of the dendritic arborization, increased vulnerability to a subsequent insult, and neurogenesis disorders in adulthood [36].

Albeit not reaching statistical significance, corticosterone serum levels were higher after PMS compared to controls. Corticosterone serum levels were measured on postnatal day 14 , $10 \mathrm{~d}$ after the onset of maternal separation. At the end of the second postnatal week, mice usually have access to mixed feeding and are not so dependent of breast milk. Perhaps during early maternal separation, when the mice are highly dependent on maternal care, corticosterone levels would be more affected. Thus, we cannot rule out the possibility that early changes in corticosterone levels have influenced hippocampal alterations seen in our study. Hsu et al, after performing handling and maternal separation in Sprague-Dawley rats on postnatal days 9 (for $30 \mathrm{~min}$ ) and 10 (for $6 \mathrm{~h}$ ), did not find difference in corticosterone levels compared to unseparated pups on postnatal day 10. Nonetheless, these authors identified later alterations in GABA neurotransmission into adulthood [37].

The large intragroup variation in corticosterone levels in our study among separated suckling mice may be a result of a greater competition for breastmilk compared with nourished counterparts. We speculate that among the undernourished, separated mice, the dominant pups would have slightly more access to the breastmilk and therefore be less stressed while returned to the dams as opposed to the non-dominant siblings, an effect that may partly explain these variations.

Early neonatal stress may induce lasting hippocampal changes that may go into adulthood. Significant reductions in 

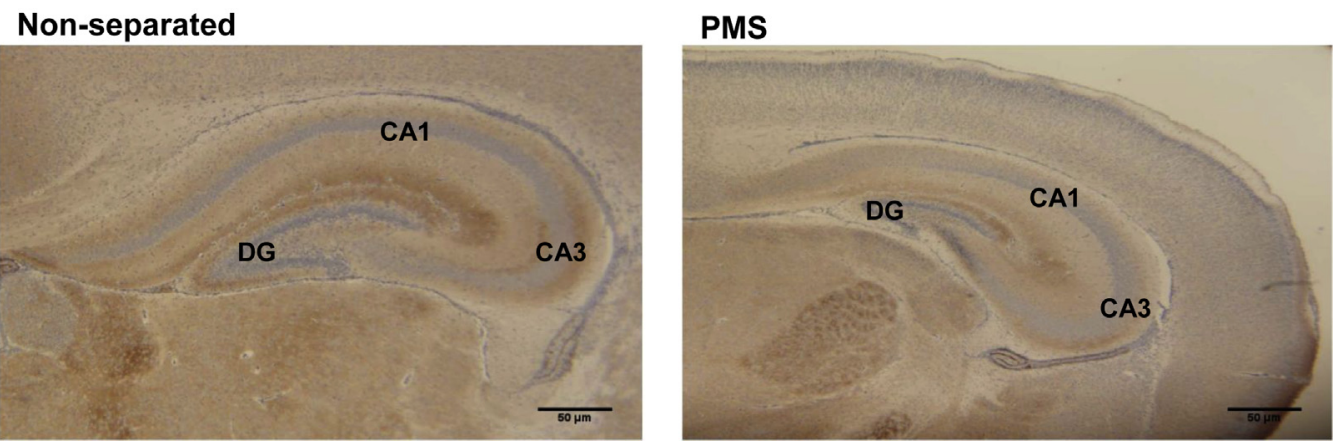

Fig. 6. Representative hippocampal synaptophysin (SYN) immunohistochemistry from experimental groups, $100 \mathrm{X}$. $\mathrm{N}=5 \mathrm{for}$ each group. Scale bar: $50 \mu \mathrm{m}$.

hippocampal volume (71\%) and size of pyramidal (62\%) and granular $(60 \%)$ cell layers of the adult hippocampus have been found after early-life maternal deprivation [38].

Oreland and colleagues did not find significant differences in the volumes of CA1, CA2, and CA3 fields or DG of the hippocampus in 3-wk-old rats separated either by 15 min or 6 h daily during the first $21 \mathrm{~d}$ of postnatal life. However, they found a reduction in numerical density of neurons in DG and CA3 in the 6 h-separation group [39]. Studies using other models of protein deprivation both prenatally [40] and postnatally [41] did find decreases in the number of CA1 pyramidal cells and irreversible loss of hippocampal cholinergic and GABAergic interneurons, respectively. In an earlier study from our group, breastmilkdeprived suckling pups raised in large litters did not show differences in CA1 numerical neuronal density, area, and volume. However, an increase in the volume of CA1 pyramidal neurons was found in the undernourished group, suggesting cell degeneration [25].

Despite no changes in the total cell number in the hippocampal regions, this study found reductions in the CA1 pyramidal cell layer area and CA3 area and volume. CA1 and CA3 synaptic neuron connections are very important for learning as a key piece of the trisynaptic circuitry of the hippocampus [42]. Presumably, factors such as loss of neuronal and glial extensions may have contributed to these volume/area changes, regardless of cell numbers.

The amino acids glutamate, $\gamma$-aminobutyric acid, glycine, aspartate, and taurine are neurotransmitters and neuromodulators in the central nervous system [43]. Glutamate is critical for hippocampal circuitry development and synapses and an important mediator of emotional and cognitive behaviors [44]. Gamma aminobutyric acid has been described as an excitatory neurotransmitter in the neonatal brain, playing a role in synaptic plasticity in the hippocampus circuits [45], and may have a protective role to hippocampal pyramidal neurons against hypoxia-ischemia injury in neonatal mice [46].

Pickering et al have found diminished hippocampal RNA expression of NMDA NR2B, AMPA GluR1, and GluR2 25 weeks after 6 h daily maternal separation during postnatal days 1 to 21 [47]. In our study, we found decreased hippocampal levels of glutamate in the PMS group compared to the controls at $14 \mathrm{~d}$ of age.

Similar to our findings, Ladd et al. found lower hippocampal levels of aspartate and glycine in the undernourished mice [25]; however, these effects were not reversed by glutamine and zinc treatment. In addition, Rotta et al., after inducing protein malnutrition in young rats by restricting the protein content of the mother's diet during pregnancy and lactation, have found reduced $\mathrm{Na}^{+}$-independent glutamate binding in the cell membranes of the cerebral cortex and low vesicular uptake [48].

Prolonged maternal separation diminished leptin and IGF-1 serum levels in 14-d-old mice, an effect also associated with systemic inflammation and similar to what was found in Zimbabwean stunted children [9]. Reduced circulating leptin and increased corticosterone levels were found after neonatal maternal deprivation on postnatal days 9 and 10 (a critical period for hypothalamus development) by 24-h separation [49].

Viveros et al. have found increased hypothalamic leptin receptor mRNA levels $24 \mathrm{~h}$ after maternal separation (on day 9) in both genders, levels that were normalized in females $12 \mathrm{~h}$ later but not in males. Hypothalamic IGF-1 mRNA levels were found to be significantly lower after $24 \mathrm{~h}$ of maternal separation [49]. In another study by the same group, 24-h maternal-separated rats (on day 9) and euthanized rats on days 13, 35, and 75 showed significant reduced leptin plasma levels only on day 75. Adiponectin levels were also reduced by day 75 in females. They did not find changes in hypothalamic levels of IGF-1 and leptin receptor mRNAs [50]. Interestingly, in the hypothalamus, a saturable leptin-transporter takes leptin more rapidly in lower serum leptin levels. Conversely, the hippocampus takes up leptin more rapidly at higher serum leptin levels [51], effects that may explain why no difference in hypothalamic leptin mRNA levels was found by Viveros (2010) and may in part explain the structural and functional alterations seen in the hippocampus in our study due to lower PMS-induced serum leptin levels. Leptin has been recognized to be important for hippocampal synaptic function [52]. Of note, leptin modulates GABA-ergic transmission in developing CA3 pyramidal cells of newborn rats [53], a field of the hippocampus where we found poor synaptophysin immunolabeling in PMS-challenged mice.

Peak postnatal leptin occurs around the tenth day of life. Thus, episodes of maternal separation may break this development signal [54]. Postnatal leptin has emerged as a critical factor affecting the maturation of the pituitary-hypothalamic axis and possibly of other brain regions [24,55]. In addition, leptin may influence inflammatory responses [56].

In our study, increased CRP serum levels (a marker of systemic inflammation [57]) after PMS suggests chronic inflammation, which may be related to the intestinal barrier disruption and continuous (and low grade) gut-to-blood bacterial translocation due to neonatal stress [58]. Undernutrition in the first 2 wk of postnatal life has been associated with intestinal inflammation in mice [25] and may predispose and potentiate early-life enteric infections [59,60]. Parental separation may induce a lasting inflammation going into adulthood [61]. Recently, Preidis et al after inducing undernutrition in mice with a similar model of timed maternal separation found urinary 
metabolites related with chronic inflammation and liver dysfunction [62].

Low leptin, IGF-1 levels, and body weight have been found in marasmic children [63]. Prendergast et al. (2014) found that Zimbabwean stunted children ( 6 wk to 12 mo of age) show increased CRP and AGP and reduced IGF-1 and insulin-like growth factor binding protein-3 plasma levels. In addition, stunted children (aged 3-12 mo) showed high levels of intestinal fatty acidbinding protein (a marker of intestinal cell shedding and barrier disruption) in children, supporting this relationship of intestinal barrier breakdown, inflammation, and poor IGF-1 responses. One recent clinical trial has documented improvements in linear growth and IGF-1 levels with reduced CRP circulating levels in children living in an endemic area of enteric infections following vitamin A and zinc supplementation [64], suggesting an important role of systemic inflammation regulating IGF-1-growth effects and potential benefits with nutritional interventions.

The prolonged undernutrition with restriction of breastfeeding (without access to food and water), especially during the 12-h maternal separation protocol (day 6 to day 14), may have caused transitory severe starvation and therefore been a strong driver of nutrient deficiency to the developing hippocampus. Caution is needed, though, to extrapolate our findings of this mouse model to humans, who are exposed to very complex environmental and maternal influences.

\section{Conclusions}

To the best of our knowledge, this is the first study associating maternal separation-induced undernutrition, which has led to systemic inflammation, with deficits in IGF-1 levels and growth, and hippocampal alterations. This model may be helpful to further study the gut-brain axis associated with environmental enteropathy in areas of endemic malnutrition and enteric infections in the developing world and the potential use of nutritional interventions to ameliorate these effects. Interventional studies with key brain trophic micronutrients (such as zinc supplementation) are now being planned by our laboratory to redirect the trajectory of normal hippocampal development in relationship with the intestinal microbiota (a recognized factor influencing hippocampal neurotransmission [65]) to maternalseparated mice. Our group has demonstrated the benefits of zinc supplementation to ameliorate cognitive outcomes in children at risk for malnutrition and enteric diseases [64,65].

\section{References}

[1] Pollitt E. Developmental sequel from early nutritional deficiencies: conclusive and probability judgements. J Nutr 2000;130:350S-3S.

[2] Ivanovic DM, Leiva BP, Perez HT, Almagia AF, Toro TD, Urrutia M, et al Nutritional status, brain development and scholastic achievement of Chilean high-school graduates from high and low intellectual quotient and socio-economic status. Br J Nutr 2002;87:81-92.

[3] Ivanovic DM, Leiva BP, Perez HT, Inzunza NB, Almagia AF, Toro TD, et al. Long-term effects of severe undernutrition during the first year of life on brain development and learning in Chilean high-school graduates. Nutrition 2000;16:1056-63.

[4] Benitez-Bribiesca L. De la Rosa-Alvarez I, Mansilla-Olivares A. Dendritic spine pathology in infants with severe protein-calorie malnutrition. Pediatrics 1999;104:e21.

[5] Beas-Zarate C, Ortuno-Sahagun D, Angel Meza AR, Feria-Velasco A. Effect of a corn diet during development on $[3 \mathrm{H}]$-spiperone binding in the brain of rats at the perinatal stage. Comp Biochem Physiol A Physiol 1995;112:161-6.

[6] Mirescu C, Peters JD, Gould E. Early life experience alters response of adult neurogenesis to stress. Nat Neurosci 2004;7:841-6.

[7] Nishi M, Horii-Hayashi N, Sasagawa T. Effects of early life adverse experiences on the brain: implications from maternal separation models in rodents. Front Neurosci 2014;8:166.
[8] Calikoglu A, Karayal A, D’Ercole A. Nutritional regulation of IGF-I expression during brain development in mice. Pediatr Res 2001;49:197-202.

[9] Prendergast AJ, Rukobo S, Chasekwa B, Mutasa K, Ntozini R, Mbuya MN, et al. Stunting is characterized by chronic inflammation in Zimbabwean infants. PLoS One 2014;9:e86928.

[10] Yu DX, Marchetto MC, Gage FH. How to make a hippocampal dentate gyrus granule neuron. Development 2014;141:2366-75.

[11] Rotstein M, Bassan H, Kariv N, Speiser Z, Harel S, Gozes I. NAP enhances neurodevelopment of newborn apolipoprotein E-deficient mice subjected to hypoxia. J Pharmacol Exp Ther 2006;319:332-9.

[12] Tanaka T. Effects of litter size on behavioral development in mice. Reprod Toxicol 1998;12:613-7.

[13] Pantaleoni GC, Fanini D, Sponta AM, Palumbo G, Giorgi R, Adams PM. Effects of maternal exposure to polychlorobiphenyls (PCBs) on F1 generation behavior in the rat. Fundam Appl Toxicol 1988;11:440-9.

[14] Palanza P, Parmigiani S, vom Saal FS. Effects of prenatal exposure to low doses of diethylstilbestrol, o,p'DDT, and methoxychlor on postnatal growth and neurobehavioral development in male and female mice. Horm Behav 2001;40:252-65.

[15] Monassi CR, Leite-Panissi CR, Menescal-de-Oliveira L. Ventrolateral periaqueductal gray matter and the control of tonic immobility. Brain Res Bull 1999;50:201-8.

[16] Andrade JP, Madeira MD, Paula-Barbosa MM. Effects of long-term malnutrition and rehabilitation on the hippocampal formation of the adult rat. A morphometric study. J Anat 1995;187:379-93.

[17] Gundersen HJ, Jensen EB, Kieu K, Nielsen J. The efficiency of systematic sampling in stereology-reconsidered. J Microsc 1999;193:199-211.

[18] Chen F, Madsen TM, Wegener G, Nyengaard JR. Changes in rat hippocampal CA1 synapses following imipramine treatment. Hippocampus 2008;18:631-9.

[19] Hosseini-Sharifabad M, Nyengaard JR. Design-based estimation of neuronal number and individual neuronal volume in the rat hippocampus. J Neurosci Methods 2007;162:206-14.

[20] Baddeley AJ, Gundersen HJ, Cruz-Orive LM. Estimation of surface area from vertical sections. J Microsc 1986;142:259-76.

[21] Gundersen HJ. Estimators of the number of objects per area unbiased by edge effects. Microsc Acta 1978;81:107-17.

[22] Paxinos G, Franklin KBJ. The mouse brain in stereotaxic coordinates. San Diego: Academic Press; 2001.

[23] Nyengaard JR. Stereologic methods and their application in kidney research. J Am Soc Nephrol 1999;10:1100-23.

[24] Marco EM, Llorente R, Lopez-Gallardo M, Mel V, Llorente-Berzal A, Prada C, et al. The maternal deprivation animal model revisited. Neurosci Biobehav Rev 2015;51:151-63.

[25] Ladd FV, Ladd AA, Ribeiro AA, Costa SB, Coutinho BP, Feitosa GA, et al. Zinc and glutamine improve brain development in suckling mice subjected to early postnatal malnutrition. Nutrition 2010;26:662-70.

[26] Zhang Y, Li N, Yang J, Zhang T, Yang Z. Effects of maternal food restriction on physical growth and neurobehavior in newborn Wistar rats. Brain Res Bull 2010;83:1-8.

[27] Miki T, Yokoyama T, Kusaka T, Suzuki S, Ohta K, Warita K, et al. Early postnatal repeated maternal deprivation causes a transient increase in OMpg and BDNF in rat cerebellum suggesting precocious myelination. J Neurol Sci 2014;336:62-7.

[28] Subramanian HH, Holstege G. The midbrain periaqueductal gray changes the eupneic respiratory rhythm into a breathing pattern necessary for survival of the individual and of the species. Prog Brain Res 2014;212:351-84.

[29] Vianna DM, Brandao ML. Anatomical connections of the periaqueductal gray: specific neural substrates for different kinds of fear. Braz J Med Biol Res 2003;36:557-66.

[30] Monassi CR, Hoffmann A, Menescal-de-Oliveira L. Involvement of the cholinergic system and periaqueductal gray matter in the modulation of tonic immobility in the guinea pig. Physiol Behav 1997;62:53-9.

[31] Barros KM, Manhaes-De-Castro R, Lopes-De-Souza S, Matos RJ, Deiro TC, Cabral-Filho JE, et al. A regional model (Northeastern Brazil) of induced mal-nutrition delays ontogeny of reflexes and locomotor activity in rats. Nutr Neurosci 2006;9:99-104.

[32] Andersen SL, Teicher MH. Delayed effects of early stress on hippocampal development. Neuropsychopharmacology 2004;29:1988-93.

[33] Lopes da Silva FH, Arnolds DE. Physiology of the hippocampus and related structures. Annu Rev Physiol 1978;40:185-216.

[34] McEwen BS, Nasca C, Gray JD. Stress effects on neuronal structure: Hippocampus, amygdala and prefrontal cortex. Neuropsychopharmacology 2016;41:3-23.

[35] Sapolsky RM. Glucocorticoids and hippocampal atrophy in neuropsychiatric disorders. Arch Gen Psychiatry 2000;57:925-35.

[36] Gould E, Tanapat P, Rydel T, Hastings N. Regulation of hippocampal neurogenesis in adulthood. Biol Psychiatry 2000;48:715-20.

[37] Hsu FC, Zhang GJ, Raol YS, Valentino RJ, Coulter DA, Brooks-Kayal AR. Repeated neonatal handling with maternal separation permanently alters hippocampal GABAA receptors and behavioral stress responses. Proc Natl Acad Sci U S A 2003;100:12213-8.

[38] Aksic M, Radonjic NV, Aleksic D, Jevtic G, Markovic B, Petronijevic N, et al. Long-term effects of the maternal deprivation on the volume and number 
of neurons in the rat neocortex and hippocampus. Acta Neurobiol Exp (Wars ) 2013;73:394-403.

[39] Oreland S, Nylander I, Pickering C. Prolonged maternal separation decreases granule cell number in the dentate gyrus of 3-week-old male rats. Int J Dev Neurosci 2010;28:139-44.

[40] Lister JP, Tonkiss J, Blatt GJ, Kemper TL, DeBassio WA, Galler JR, et al. Asymmetry of neuron numbers in the hippocampal formation of prenatally malnourished and normally nourished rats: a stereological investigation. Hippocampus 2006;16:946-58.

[41] Andrade JP, Paula-Barbosa MM. Protein malnutrition alters the cholinergic and GABAergic systems of the hippocampal formation of the adult rat: an immunocytochemical study. Neurosci Lett 1996;211:211-5.

[42] Gruart A, Delgado-Garcia JM. Activity-dependent changes of the hippocampal CA3-CA1 synapse during the acquisition of associative learning in conscious mice. Genes Brain Behav 2007;6:S24-31.

[43] Perry M, Li Q, Kennedy RT. Review of recent advances in analytical techniques for the determination of neurotransmitters. Anal Chim Acta 2009;653:1-22.

[44] Molnar E, Pickard L, Duckworth JK. Developmental changes in ionotropic glutamate receptors: lessons from hippocampal synapses. Neuroscientist 2002;8:143-53.

[45] Gaiarsa JL. Plasticity of GABAergic synapses in the neonatal rat hippocampus. J Cell Mol Med 2004;8:31-7.

[46] Azimi-Zonooz A, Shuttleworth CW, Connor JA. GABAergic protection of hippocampal pyramidal neurons against glutamate insult: deficit in young animals compared to adults. J Neurophysiol 2006;96:299-308.

[47] Pickering C, Gustafsson L, Cebere A, Nylander I, Liljequist S. Repeated maternal separation of male Wistar rats alters glutamate receptor expression in the hippocampus but not the prefrontal cortex. Brain Res 2006;1099:101-8.

[48] Rotta LN, Leszczinski DN, Brusque AM, Pereira P, Brum LF, Nogueira CW, et al. Effects of undernutrition on glutamatergic parameters in the cerebral cortex of young rats. Physiol Behav 2008;94:580-5.

[49] Viveros MP, Diaz F, Mateos B, Rodriguez N, Chowen JA. Maternal deprivation induces a rapid decline in circulating leptin levels and sexually dimorphic modifications in hypothalamic trophic factors and cell turnover. Horm Behav 2010;57:405-14.

[50] Viveros MP, Llorente R, Diaz F, Romero-Zerbo SY, Bermudez-Silva FJ, Rodriguez de FF, et al. Maternal deprivation has sexually dimorphic longterm effects on hypothalamic cell-turnover, body weight and circulating hormone levels. Horm Behav 2010;58:808-19.

[51] Banks WA. The blood-brain barrier as a regulatory interface in the gutbrain axes. Physiol Behav 2006;89:472-6.
[52] Irving AJ, Harvey J. Leptin regulation of hippocampal synaptic function in health and disease. Philos Trans R Soc Lond B Biol Sci 2014;369:20130155.

[53] Guimond D, Diabira D, Porcher C, Bader F, Ferrand N, Zhu M, et al. Leptin potentiates GABAergic synaptic transmission in the developing rodent hippocampus. Front Cell Neurosci 2014;8:235.

[54] Cottrell EC, Mercer JG, Ozanne SE. Postnatal development of hypothalamic leptin receptors. Vitam Horm 2010;82:201-17.

[55] Bouret SG, Simerly RB. Development of leptin-sensitive circuits. J Neuroendocrinol 2007;19:575-82.

[56] Fantuzzi G, Faggioni R. Leptin in the regulation of immunity, inflammation, and hematopoiesis. J Leukoc Biol 2000;68:437-46.

[57] Black S, Kushner I, Samols D. C-reactive protein. J Biol Chem 2004;279:48487-90.

[58] de Queiroz CA, Fonseca SG, Frota PB, Figueiredo IL, Aragao KS, Magalhaes CE, et al. Zinc treatment ameliorates diarrhea and intestinal inflammation in undernourished rats. BMC Gastroenterol 2014; $14: 136$.

[59] Coutinho BP, Oria RB, Vieira CM, Sevilleja JE, Warren CA, Maciel JG, et al. Cryptosporidium infection causes undernutrition and, conversely, weanling undernutrition intensifies infection. J Parasitol 2008;94:1225-32.

[60] Castro IC, Oliveira BB, Slowikowski JJ, Coutinho BP, Siqueira FJ, Costa LB, et al. Arginine decreases Cryptosporidium parvum infection in undernourished suckling mice involving nitric oxide synthase and arginase. Nutrition 2012;28:678-85.

[61] Lacey RE, Kumari M, McMunn A. Parental separation in childhood and adult inflammation: the importance of material and psychosocial pathways. Psychoneuroendocrinology 2013;38:2476-84.

[62] Preidis GA, Keaton MA, Campeau PM, Bessard BC, Conner ME, Hotez PJ. The undernourished neonatal mouse metabolome reveals evidence of liver and biliary dysfunction, inflammation, and oxidative stress. J Nutr 2014; $144: 273-81$.

[63] Haspolat K, Ece A, Gurkan F, Atamer Y, Tutanc M, Yolbas I. Relationships between leptin, insulin, IGF-1 and IGFBP-3 in children with energy malnutrition. Clin Biochem 2007;40:201-5.

[64] Adriani M, Wirjatmadi B. The effect of adding zinc to vitamin A on IGF-1, bone age and linear growth in stunted children. J Trace Elem Med Biol 2014;28:431-5.

[65] Clarke G, Grenham S, Scully P, Fitzgerald P, Moloney RD, Shanahan F, et al. The microbiome-gut-brain axis during early life regulates the hippocampal serotonergic system in a sex-dependent manner. Mol Psychiatry 2013;18:666-73. 